ORIGINAL ARTICLE

\title{
Blood Lipid Profile in Acute Coronary Syndrome and Chronic Stable Angina Patients
}

\author{
T Parvin ${ }^{1}$, MH Rahman ${ }^{2}$, S Ferdousi ${ }^{2}$, A Shahnaz ${ }^{2}$, M Mahal $^{2}$ \\ SF Ahmed ${ }^{1}$, BA Ferdous ${ }^{3}$, DAS Hussain ${ }^{4}$ \\ ${ }^{1}$ Dept of Cardiology, Bangabandhu Sheikh Mujib Medical University (BSMMU), Dhaka \\ ${ }^{2}$ Dept of Biochemistry, Dhaka Medical College, Dhaka \\ ${ }^{3}$ Dept of Biochemistry, Marks Medical college, Dhaka \\ ${ }^{4}$ Dept of Biochemistry, Shaheed Monsur Ali Medical college, Dhaka
}

\begin{abstract}
This study was designed to compare the blood lipid profile and conventional cardiovascular risk factors in patients with acute coronary syndrome (ACS) and chronic stable angina (CSA). A total of 110 patients, 55 of which were of ACS and 55 with chronic stable angina (CSA) who underwent coronary angiography in the Department of Cardiology, BSMMU, Dhaka were enrolled for the study. Lipid profile and age, sex, diabetes mellitus, hypertension, hyperlipidemia, smoking habit, family history of premature coronary artery diseases (CAD) of the patients were recorded and compared. Mean \pm SD age of the studied patients was $52.2 \pm 10$ years. Prevalence of diabetes mellitus $(\mathrm{p}<0.05)$ and hypertension $(\mathrm{p}<0.05)$ was significantly higher in patients with CSA than that with ACS. Frequency of hyperlipidemia, smoking habit and family history of CAD was similar between groups. Patients with CSA had significantly higher triple vessel diseases (TVD) $(\mathrm{p}<0.001)$ and significantly lower high-density lipoprotein cholesterol (HDLc) $(\mathrm{p}<$ 0.05) compared to that of patients with ACS. ACS patients had significantly higher single vessel diseases (SVD) ( $\mathrm{p}<0.001)$ compared to that of CSA but the distribution of low-density lipoprotein cholesterol (LDLc), total cholesterol and triglycerides were variable between groups. This study showed that CSA patients had substantially higher frequency of having some CVD risk factors with alteration in certain lipid profile parameters and higher number of triple vessels disease than patients with ACS. This might aid in selecting appropriate criteria for angiographic evaluation and better management of patients with coronary artery diseases.
\end{abstract}

Key Words: Coronary artery disease, Acute coronary syndrome, Chronic stable angina, Blood lipid profile

\section{Introduction}

Ischemic heart disease (IHD) is one the of major health problems worldwide. In developing countries, the incidence of IHD is also high and it is mostly due to an increase in atherosclerotic diseases related to demographic changes, urbanization, lifestyle modifications and higher risk factor levels such as obesity, dyslipidemia, diabetes and hypertension, the relatively early age at presentation, the large population size and the high proportion of young adults or middleaged population in these countries ${ }^{1}$. Although IHD was considered to be a result of an urban

lifestyle, recently published studies have indicated that IHD is also on the rise in rural areas. A rural population based survey in 2001 in Bangladesh shows prevalence of IHD to be $3.4 \%$ ( $4.6 \%$ in men and $2.7 \%$ in women $)^{2}$.

IHD comprises a wide spectrum of conditions including chronic stable angina (CSA) and acute coronary syndrome (ACS) and is the manifestation of single entity, Coronary Artery Disease (CAD) but varies in location, nature of lesion $^{3}$. Patients with ACS have further stratified into ST-elevation myocardial infarction (STEMI)

Bangladesh J Med Biochem 2014; 7(2): 52-56 
Blood Lipid Profile in Acute Coronary Syndrome and Chronic and non-ST-elevation myocardial infarction (NSTEMI)/unstable angina (UA). In CSA, the presence of one or more obstructions in major coronary arteries is likely and the severity of stenosis is usually greater than 70 percent $^{4}$. ACS occurs when there is atherosclerotic plaque rupture, fissuring, erosion, in combination with superimposed intracoronary thrombus formation within a coronary artery ${ }^{3}$. Coronary lesions leading to myocardial infarction have a specific angiographic morphology that is uncommon in lesions of similar severity in the non infarctrelated vessel or in vessels of patients with chronic stable angina ${ }^{5}$. The more severe and diffuse coronary atherosclerosis, in terms of number of stenoses, occlusions, diseased vessels and extent of coronary atherosclerosis, was higher in patients with uncomplicated stable angina than in those presenting with AMI or with unstable angina ${ }^{6}$. This suggests that the pathogenesis of the various phenotypes of $\mathrm{CHD}$ may differ where ACS and CSA may not share all the same risk factors ${ }^{7}$. A few cohort studies have shown that some conventional risk factors are of more predictive value for the development of either event and they have showed that some patients develop IHD early even with normal values of lipid profile ${ }^{8}$. It is, therefore, necessary to review and revise the criteria for risk assessment of IHD in the context of new data and the information available. This paper presents the status of risk factors and blood lipid profile between ACS and CSA subsets of IHD patients in a tertiary care hospital of Bangladesh.

\section{Materials and Methods}

This was an observational study done with 110 subjects admitted for coronary angiography in the Department of Cardiology, Bangabandhu Sheikh Mujib Medical University (BSMMU), Dhaka, Bangladesh from January 2009 to December 2009. Of the 110 patients, 55 were ACS patients [patients with ST elevated myocardical infarction (ST elevation in ECG and a rise in cardiac marker/s), and non-ST elevated myocardial infarction (evidence of myocardial necrosis) as well as those who had a recent history of angina at rest or minimum exertion or crescendo angina not exceeding a duration of 3 months (unstable angina) were labelled as acute coronary syndrome (ACS) ${ }^{3}$ ] and 55 were CSA patients [patients with a minimum of 2-years history of typical stable angina (predictable and reproducible central chest discomfort after physical exertion and or emotional stress and is relieved by rest or sublingual nitroglycerin) with positive ETT were defined as $\mathrm{CSA}]^{4}$. The patients were diagnosed on the basis of history, clinical presentation, ECG, echocardiogram, laboratory investigations, stress tests and angiography. Risk factors including DM, hypertension, hyperlipidemia (LDLc, total cholesterol or triglyceride is above or HDLc is below respective normal reference value either alone or in combination), and family history of premature CAD were defined on the basis of standard definitions ${ }^{9,10}$. CAD was defined as $\geq 50 \%$ luminal diameter stenosis in one or more major epicardial vessel ${ }^{11}$. The exclusion criteria were the presence of valvular heart disease, left ventricular hypertrophy, cardiomyopathy, congestive heart failure and a positive history of concomitant malignancies, liver and kidney diseases.

Demographic data including sex, age, hypertension, hyperlipidemia, DM, smoking habit and family history of premature CAD and the results of biochemical tests including fasting blood glucose and lipid profile were recorded in predesigned questionnaire form and analyzed. Medication history of the patients in each group was also recorded. Informed written consent was taken from all patients.

After 10-12 hour fasting, peripheral venous blood specimens were collected from an antecubital vein in EDTA vacutainers using disposable syringe. The blood collected was centrifuged and plasma was separated without further delay. Fasting plasma glucose was measured by the glucose-oxidase method. The blood levels of total cholesterol, HDLc and triglyceride (TG) levels were determined by enzymatic method and LDLc was calculated using Friedewald's equation ${ }^{12}$.

Continuous variables were expressed as mean \pm SD and were compared between groups of patients by student's 't' test. Categorical 
T Parvin, MH Rahman, S Ferdousi et al

variables were compared using a chi-square test or Fischer's Exact test as appropriate and were presented as absolute frequencies with percentages. All ' $\mathrm{p}$ ' values were two-tailed with significance defined as $p<0.05$ at the level of 95\% confidence limit. All analysis was done using the SPSS 16.0 (Statistical Package for Social Science) package for windows.

\section{Result}

Baseline characteristics of the patients are presented in table I. Mean \pm SD of age of the study subjects was 52.2 \pm 9.9 years and 99 of them $(90 \%)$ were male. Frequency of diabetes mellitus was significantly higher $(p<0.05)$ in patients with CSA (35\%) than that with ACS (15\%). Similarly, hypertension was also significantly higher $(\mathrm{p}<0.05)$ in CSA $(73 \%)$ than ACS $(45 \%)$ group. The prevalence of dyslipidemia $(p=0.634)$, smoking habit $(p=0.849)$ and family history of CAD $(p=0.356)$ showed no significant difference between groups.

Table I: Baseline characteristics of the study subjects

\begin{tabular}{llll}
\hline Risk factors & $\begin{array}{l}\text { ACS } \\
(\mathbf{n}=\mathbf{5 5}\end{array}$ & $\begin{array}{l}\text { CSA } \\
(\mathbf{n = 5 5 )}\end{array}$ & P value \\
\hline Age in yrs & $52.2 \pm 9.9$ & $52.2 \pm 10.1$ & 0.992 \\
Male sex n(\%) & $50(90)$ & $49(89)$ & 0.751 \\
Diabetes Mellitus & $8(15)$ & $19(35)$ & 0.026 \\
$\begin{array}{l}\text { Dyslipidemia } \\
\text { Hypertension }\end{array}$ & $43(78)$ & $45(82)$ & 0.634 \\
$\begin{array}{l}\text { Smoking } \\
\text { Family history }\end{array}$ & $25(45)$ & $40(73)$ & 0.006 \\
of CAD & $14(25)$ & $29(53)$ & 0.849 \\
\hline
\end{tabular}

Data are mean $\pm(\mathrm{SD})$ and $\mathrm{n}(\%)$ for continuous and categorical variables respectively

Table II shows the distribution of angiographically detected vessel diseases. While the frequency of SVD was significantly higher $(p<0.001)$ in patients with ACS (64\%) than that with CSA (10\%) and that of TVD significantly lower $(p<0.001)$ in patients with ACS (11\%) than that with CSA (51\%), it was almost similar for DVD in both groups. Normal angiogram was found in $4 \%$ and $11 \%$ in ACS and CSA group respectively.
Table-II: Angiographically detected vessel diseases:

\begin{tabular}{llll}
\hline $\begin{array}{l}\text { Vessel Diseases, } \\
\text { n(\%) }\end{array}$ & $\begin{array}{l}\text { ACS } \\
(\mathbf{n}=\mathbf{5 5})\end{array}$ & $\begin{array}{l}\text { CSA } \\
(\mathbf{n}=\mathbf{5 5})\end{array}$ & P value \\
\hline Normal angiogram & $02(04)$ & $06(11)$ & \\
SVD & $35(64)$ & $10(18)$ & $<0.001$ \\
DVD & $12(22)$ & $11(20)$ & 1.000 \\
TVD & $06(11)$ & $28(51)$ & $<0.001$ \\
\hline
\end{tabular}

Data are n (\%). SVD: single vessel disease, DVD: double vessel disease, TVD: triple vessel disease

Table III demonstrates the blood lipid profile of the study subjects. Blood concentrations of HDL-C was found to be significantly higher ( $p$ $<0.05)$ in patients with ACS $(39.4 \mathrm{mg} / \mathrm{dl})$ compared to that with CSA $(35.6 \mathrm{mg} / \mathrm{dl})$. The patients with ACS had higher LDL-C (124.5 $\mathrm{mg} / \mathrm{dl}$ vs. $123.3 \mathrm{mg} / \mathrm{dl})$, total cholesterol $(205 / 7$ $\mathrm{mg} / \mathrm{dl}$ vs. $199.8 \mathrm{mg} / \mathrm{dl}$ ) and lower triglycerides $(193.4 \mathrm{mg} / \mathrm{dl}$ vs. $203.3 \mathrm{mg} / \mathrm{dl})$ than the patients with CSA but there was no significant differences between the groups.

Table-III: Blood lipid profile of the study subjects

\begin{tabular}{llll}
\hline $\begin{array}{l}\text { Blood lipid } \\
\text { profile }(\mathrm{mg} / \mathrm{dl})\end{array}$ & $\begin{array}{l}\text { ACS } \\
(\mathbf{n}=\mathbf{5 5})\end{array}$ & $\begin{array}{l}\text { CSA } \\
(\mathbf{n}=\mathbf{5 5})\end{array}$ & P value \\
\hline HDLc & $39.4 \pm 9.7$ & $35.6 \pm 7.7$ & 0.025 \\
LDLc & $124.5 \pm 45.1$ & $123.3 \pm 31.9$ & 0.874 \\
Tc & $205.7 \pm 66.6$ & $199.8 \pm 44.1$ & 0.590 \\
Triglycerides & $193.4 \pm 82.9$ & $203.3 \pm 76.0$ & 0.517 \\
\hline
\end{tabular}

Data are mean $\pm(\mathrm{SD})$. LDLc: Low-density lipoprotein cholesterol; HDLc: High-density lipoprotein cholesterol; Tc: Total cholesterol

\section{Discussion}

This study compared several risk factors including age, sex, diabetes mellitus, hypertension, smoking habit, family history of CAD and blood lipid profile between acute coronary syndrome (ACS) and chronic stable angina (CSA) patients undergoing coronary angiography in a tertiary care setting in Dhaka, Bangladesh.

In this study, mean \pm SD age of the ACS subjects was $52.2 \pm 9.9$ years, and that of CSA was $52.2 \pm 10.1$ years $(p>0.05)$. Similar mean 
Blood Lipid Profile in Acute Coronary Syndrome and Chronic age of ACS and CSA subjects was also reported in the study done by Kassaian et $\mathrm{al}^{13}$ and Vasheghani-Farahani et $\mathrm{al}^{14}$. Lower female percentage $(10 \%)$ in our study may be due to social habits that restrict women seeking medical help even with serious illness. Safiuddin ${ }^{15}$ also found a higher prevalence of male which was (98\%) in AMI and $84 \%$ in stable angina.

Among the major risk factors considered in this study, the prevalence of diabetes mellitus ( $p$ $<0.05)$ and hypertension $(p<0.05)$ were significantly higher in patients with CSA than that with ACS. Although, the frequency of dyslipidemia $(p=0.634)$ and smoking habit $(p=0.849)$ were higher and that of family history of CAD ( $p=0.356)$ was lower in CSA than ACS but there was no significant difference between groups. Bogaty et $\mathrm{al}^{10}$ and Safiuddin ${ }^{15}$ found similar significantly higher prevalence of hypertension and diabetes with stable angina in addition to strong association of smoking habit with AMI. Kassaian et $\mathrm{al}^{13}$ in their study showed an association of hypertension and positive family history in patients with ACS, hyperlipidemia in SA, but failed to show any significant association of diabetes and smoking habit between the groups. Vasheghani-Farahani et $\mathrm{al}^{14}$ reported significantly higher prevalence of hypertension, smoking habit and famlily history in patients with CSA than that with ACS but found no significant difference in prevalence of diabetes mellitus and hyperlipidemia between them. The prevence of diabetes mellitus and hyperlipidemia were found to be higher in the present study when compared to the findings of other studies ${ }^{10,16}$ which might be related to the global epidemiological transition including rapid urbanization and higher risk factors prevalent in the developing countries ${ }^{17}$.

Our study showed that the prevalence of TVD was significantly higher in CSA $(p<0.001)$ than SVD, whereas SVD was significantly more in ACS $(p<0.001)$ than TVD. DVD was almost identical in both groups. Our findings are in agreement with the findings of Bogaty et al ${ }^{10}$ and Safiuddin ${ }^{15}$.

In our study, blood HDLc was significantly lower in patients with CSA than that with ACS
$(35.6 \pm 7.7 \mathrm{mg} / \mathrm{dl}$ vs. $39.4 \pm 9.7 \mathrm{mg} / \mathrm{dl} ; \mathrm{p}$ $<0.05)$. CSA patients had also lower blood LDLc and total cholesterol (Tc) level and higher blood triglyceride level than ACS patients but the fingings showed no significant difference $(p=0.874, p=0.590, p=0.517$, respectively). Jean-Philippe Empana et al. reported simillar HDLc, higher LDLc and lower TG in SA than ACS cases in PRIME study $^{7}$. Vasheghani-Farahani et al. reported higher HDLc, LDLc and Tc but lower TG levels in patients with stable angina than patients of ACS without any significant difference. However, Bhagwat et al. found significantly lower HDLc but significantly higher other lipid profile parameters in ACS than that of CSA and control subjects in their study $^{8}$.

This study had potential limitations as it lacked a healthy age and sex matched controls to compare with ACS and CSA patients and the study was done in highly selected group of patients, comprising small cohorts in one hospital only and hence may not reflect the true picture of Bangladeshi patients. In conclusion we can say that, all the major risk factors were found to be variably associated in both the groups. Hypertension, diabetes mellitus, triple vessel diseases and lower blood HDLc were significantly more prevalent among the patients with chronic stable angina than that in patients with acute coronary syndrome.

\section{References}

1. Yusuf S, Reddy S, Ônpuu S, Anand S. Global Burden of Cardiovascular Diseases: Part I: General Considerations, the Epidemiologic Transition, Risk Factors, and Impact of Urbanization. Circulation 2001; 104: 2746-53.

2. Zaman MM, Ahmed J, Choudhury SR, Numan SM, Parvin K, Islam MS. Prevalence of ischemic heart disease in a rural population of Bangladesh. Indian Heart J 2007; 59: 214-7.

3. Kim MC, Kini AS, Fuster V. Definitions of acute coronary syndrome. In: Fuster V, ?ÓRourke RA, Walsh RA, Wilson PP editors. Hurst's The Heart. 12th ed. New York: McGraw Hill; 2008. p. 13111320 
4. Morrow DA, Gersh BJ. Chronic Coronary Artery Disease. In: Libby P, Bonow RO, Mann DL, Zipes DP, editors. Braunwald's Heart Disease: A Textbook of Cardiovascular Medicine. 8th ed. Philadelphia: Saunders; 2008. p. 1353-1418

5. Robert FW, Myrl DH, Carl WW. Pathophysiology and natural history: Unstable angina. Quantitative angiographic morphology of coronary stenoses leading to myocardial infarction or unstable angina. Circulation 1986; 73: 286-293

6. Domenico C,Francesco C, Antonino B,Carlo T, Enrico VS,Maria LF,Filippo C. Comparison of coronary angiographic narrowing in stable angina pectoris, unstable angina pectoris, and in acute myocardial infarction. Am J Cardiol 1995; 76: 215-2 19 .

7. Jean-Philippe E, Florence C-P, Gerald L, Irene JV, Pierre M, Dominique A, Jean F, Philippe A, Annie B, Michelle M, Jean-Bernard R, Bernadette H, Alun E, Pierre D. Contribution of novel biomarkers to incident stable angina and acute coronary syndrome: the PRIME Study. European Heart Journal 2008; 29: 1966-1974

8. Bhagwat VR, Yadav AS, Rathod IM. Homocysteine, lipid indices and antioxidants in patients with ischaemic heart disease from Maharashtra, India. Singapore Med J 2009; 50: 418-424

9. Chobanian AV, Bakris GL, Black HR, Cushman WC, Green LA, Izzo JL, et al. Seventh Report of the Joint National Committee on Prevention, Detection, Evaluation, and Treatment of High Blood Pressure. Hypertension 2003; 42: 1206-52.

10. Bogaty P, Brekcker SJ, White SE, Stevenson RN, El-Tam H, Balcon R, Maseri A. Comparison of coronary angiographic findings in acute and chronic first presentation of ischemic heart disease. Circulation 1993; 87: 1938-1946.
11. Biter S, Kern MJ. Angiographic data. In Kern KJ, ed. The Cardiac Catheterization Handbook, 4th edn, Mosby, Stylus, Missouri, USA, 1999. 224-247

12. Friedewald WT, Levy RI, and Fredrickson DS. Estimation of the concentration of low-density lipoprotein cholesterol in plasma, without use of the preparative ultracentrifuge. Clin Chem 1972; 18: 499 - 502.

13. Kassaian SE, Sahebjam M, Salarifar M, Alidoosti M, Zeinali AH, Saleh DKl. Predictors of long-term outcome in patients with acute coronary syndrome undergoing percutaneous coronary intervention: A single center registry (THCR). J Tehran Uni Heart Cen 2006; 1: 155-161

14. Vasheghani-Farahani A, Nouri N, Seifirad S, Fathollahi MS, Hakki E, Alidoosti M, Davoodi G, Masoudkabir F, Poorhosseini H. Comparison of cardiovascular risk factors and biochemical profile in patients with cardiac syndrome $\mathrm{X}$ and obstructive coronary artery disease: A propensity score-matched study. ARYA Atheroscler 2013; 9: 269-273

15. Shafiuddin M. Coronary Angiographic Comparison between Unheralded Acute Myocardial Infarction and Uncomplicated Stable Angina Pectoris. MD thesis, Dhaka University, Bangladesh; 1998

16. Ellis SG, Vandormael MG, Cowley MJ, DiSciascio G, Deligonul U, Topol EJ. Coronary morphologic and clinical determinants of procedural outcome with angioplasty for multivessel coronary disease. Implications for patient selection. Circulation 1990; 82: 1193-1202

17. The World Health Report. Making a Difference. Geneva: World Health Organization; 1999 